\title{
Influence of the inclination angle of stiffeners on folding during superplastic forming of corrugated core panels
}

\author{
A. A. Kruglov ${ }^{\dagger, 1}$, R. R. Mulyukov ${ }^{1}$, O. A. Rudenko ${ }^{1}$, A. F. Karimova ${ }^{2}$, F. U. Enikeev ${ }^{2}$ \\ †alexform1960@mail.ru \\ ${ }^{1}$ Institute for Metals Superplasticity Problems RAS, 39 S. Khalturin St., Ufa, 450001, Russia \\ ${ }^{2}$ Ufa State Petroleum Technological University (USPTU), 1 Kosmonavtov St., Ufa, 450062, Russia
}

\begin{abstract}
Superplastic forming of thin sheet corrugated structures is of special interest in developing aircraft technologies of new generation. The manufacture of such structures includes pressure welding of a package of three sheet blanks, consisting of two outer skin sheets and one inner core blank. The stop-off coating is applied to the inner surfaces of the skin sheets before welding. During superplastic forming of the package, the skin sheets take the form of a die cavity, while the core sheet stretches between the skins to form stiffeners. One of the main problems in manufacturing three-layer structures is known to be the formation of folds on the outer surface of the skins. The paper reports on studies of the influence of the inclination angle of stiffeners on folding. The choice of skin sheets with a thickness exceeding the thickness of the core sheet by $2-3$ times may prevent the formation of folds. However, when manufacturing the corrugated structures of variable cross-section, such as hollow fan blades of an aircraft engine, the recommended ratio may not always be implemented. Moreover, its performance is limited by the permissible weight of the blade. In the present study, finite element modeling of the process of superplastic forming of three-layer structures made of titanium sheet alloy VT6 (analog of Ti-6Al-4V) is done using ANSYS software. According to the simulation results, it was found that with an increase in the inclination angle of the ribs, the holding time under pressure should be increased.
\end{abstract}

Keywords: superplastic forming, corrugated core panel, folding, modeling.

\section{Introduction}

Corrugated panels are made of three sheets using the superplastic forming/diffusion bonding (SPF/DB) [1-5]. After applying the stop-off coating, the sheets are assembled into a package, connecting the outer skin sheets with an inner core sheet in areas without a stop-off coating. Then the package is subjected to SPF in the die. Stretching between the skins, the inner core sheet forms ribs. The angle of inclination of the ribs to the skin may be adjusted by changing the pattern of the stop-off coating. In $[6,7]$, it was noted that the formation of folds depends on the angle of inclination of the stiffeners. The larger the angle of inclination, the more likely becomes the formation of folds. A well-known technique to prevent folding is to choose sheets of skins with a thickness that is $2-3$ times greater than the thickness of the core sheet $[7,8]$. However, in manufacturing corrugated structures of variable cross section, for example, hollow blades of an aircraft engine fan [9-11], the recommended ratio may not always be realized. Moreover, its implementation is limited by the allowable weight of the blade. Other well-known methods for preventing folding include [12]:

- use of technological sheets;

- coarsening of the microstructure of the skin sheets by means of heat treatment;

- the use of rolling support tooling [13,14];

- the production of a core sheet from a titanium alloy, more ductile than the alloy of skin sheets [15];
- the production of a sheet of core from a material with an ultrafine-grained structure, and sheets of skin with a finegrained structure $[16,17]$;

- the increase in forming time.

In [18] it is shown that at an inclination angle of $35^{\circ}$, the formation of folds can be avoided by choosing the mode of holding the structure under pressure. The purpose of the present study is to determine the degree of influence of the angle of inclination of the stiffeners of the corrugated structure on folding.

\section{Modeling procedure and results}

Fig. 1 shows schematically a fragment of a corrugated core panel. The core sheet of thickness $s$ is placed between two skin sheets of thickness $s_{s}$. All three sheets are made of commercial titanium alloy VT6 (Ti-6Al-4V). The pressure from inert gas is applied to the free surfaces of the inner cavities of the edge welded envelope. The temperature of SPF is equal to $900^{\circ} \mathrm{C}[1,2]$. The height of the structure $H$ is equal

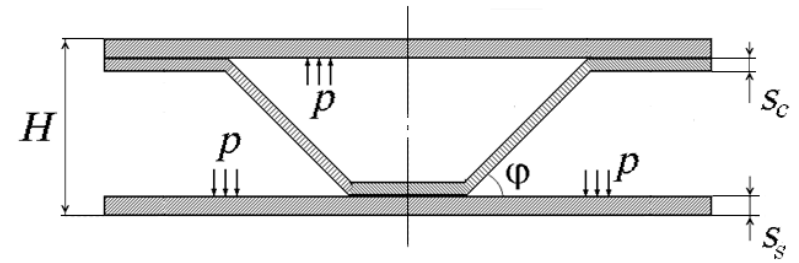

Fig. 1. Fragment of a corrugated core panel. 
to the distance between the flat plates of the die. The angle between the ribs and the skin is denoted as $\varphi$.

Finite element modeling is effected by using ANSYS 10ED. The formulation of the boundary value problem has been set in terms of creep theory using the Norton model described in detail in [19]. The standard power law of superplastic flow has been included into the formulation of the boundaryvalue problem of creep theory as follows $\sigma=K \xi^{m}$ or $\xi=C \sigma^{n}$, where $\sigma$ is the flow stress, $\xi$ is the strain rate; $K, m, C, n$ are the material constants to be determined experimentally. The values of $K$ and $m$ have been chosen as follows [20].

The time cycle of pressure change included two stages. At the initial stage, the pressure increased from 0.1 MPa to $2 \mathrm{MPa}$ for $300 \mathrm{~s}$ (Ramped mode of calculation). At the second stage, the exposure was held at constant pressure $p_{\max }$ (Stepped mode). The value of $p_{\max }$ was $4 \mathrm{MPa}$. The results of finite element calculations for various values of $\varphi$ are collected in Table 1. The diagram of the distribution of the first principal strain when $\varphi=60^{\circ}, p_{\max }=4 \mathrm{MPa}$ and holding time $3000 \mathrm{~s}$ are shown in Fig. 2 a.

Since the maximum value of pressure $p_{\max }$ is restricted due to technical reasons, the manufacture of corrugated plates without folds when $p_{\max }=4 \mathrm{MPa}$ with different values of $\varphi$ becomes possible by increasing the holding time. Table 2 shows the results of modeling SPF of corrugated panels when $\varphi=60^{\circ}, p_{\max }=4 \mathrm{MPa}$, and the holding time is $3000,4800,6000$ and $7200 \mathrm{~s}$.

It is known [7] that the elimination of folding may be achieved by increasing the thickness of the skin sheets by 2-3 times as compared with the core sheet. This will reduce the holding time. To verify the efficiency of this technique, additional finite element calculations have been fulfilled with $s_{s}=1.6 \mathrm{~mm} ; s_{c}=0.8 \mathrm{~mm} ; \varphi=60^{\circ}, p_{\max }=4 \mathrm{MPa}$ and the holding time of $3000 \mathrm{~s}$ (Fig. 2 b).

\section{Discussion}

The results of finite element modeling confirm the known fact that the formation of folds on the outer surface of the corrugated panels is affected by the angle of inclination of the stiffeners $\varphi$. The technological parameters of the SPF process are to be adjusted according to the $\varphi$ value. For example, to eliminate folding in the corrugated structure of the angle $\varphi=50^{\circ}$, when the thickness of the skin sheets is equal to the thickness of the core sheet, it is enough to hold the package

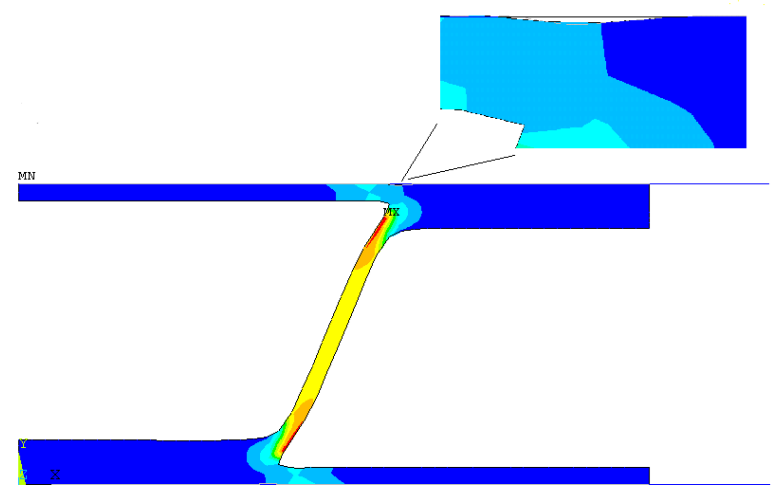

a
Table 1. Results of finite element calculations with different tilt angles of ribs $\varphi$.

\begin{tabular}{|c|c|c|c|c|}
\hline \multicolumn{5}{|c|}{$p_{\max }=4 \mathrm{M \Pi a}$, holding time $3000 \mathrm{~s}$} \\
\hline$\varphi$ & $45^{\circ}$ & $50^{\circ}$ & $55^{\circ}$ & $60^{\circ}$ \\
\hline \multicolumn{5}{|c|}{ Depth of the fold, $\mathrm{mm}$} \\
\hline & No folds & No folds & 0.037 & 0.058 \\
\hline
\end{tabular}

Table 2. Results of finite element calculations for corrugated panel with different holding time $(\tau)$.

\begin{tabular}{|c|c|c|c|c|}
\hline \multicolumn{5}{|c|}{$\varphi=60^{\circ}, p_{\max }=4 \mathrm{M \Pi a}$} \\
\hline$\tau, \mathrm{s}$ & 3000 & 4800 & 6000 & 7200 \\
\hline \multicolumn{5}{|c|}{ Depth of the fold, mm } \\
\hline & 0.058 & 0.002 & No folds & No folds \\
\hline
\end{tabular}

for $3000 \mathrm{~s}$ under $p_{\max }=4 \mathrm{M \Pi}$. At the same time for the case when $\varphi=55^{\circ}$, folds are formed on the outer surface of the skins, and so the required holding time is $6000 \mathrm{~s}$.

The value of $p_{\max }$ is restricted in accordance with the technical capabilities of the available equipment for SPF. Therefore, an important role in the manufacture of corrugated structures is played by the exposure time under $p_{\text {max }}$. According to the results of calculations, it is found that for each angle $\varphi$ (the value of $p_{\max }$ does not change) there is a certain holding time required for smoothing the folds. For example, folds occur at $\varphi=60^{\circ}$ and $p_{\max }=4 \mathrm{MPa}$ after holding for $4800 \mathrm{~s}$. At the same time folds are not observed after holding for $6000 \mathrm{~s}$. The following two possible ways to solve the problem of folding can be suggested now. Let us consider both of them using the example of a corrugated panel with the angle $\varphi=60^{\circ}$. First, for the structures with equal thicknesses of the core sheet and skins it is enough to increase the holding time under $p_{\max }=4 \mathrm{MPa}$ up to $6000 \mathrm{~s}$. Second, to reduce the holding time to $3000 \mathrm{~s}$, it is necessary to increase the thickness of the skin sheet by 2 times as compared with the thickness of the core sheet.

\section{Summary}

According to the results of finite element modeling of the SPF process of three-layer corrugated panels, the formation of external folds is found to depend on the angle of inclination of the stiffening ribs, when the thickness of the skin sheet does not exceed the thickness of the core sheet. As the angle

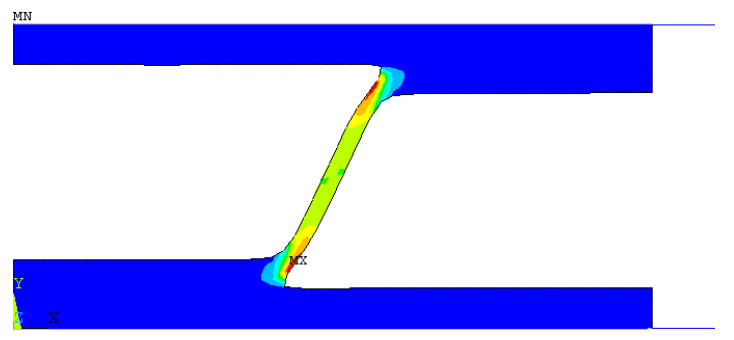

$\mathrm{b}$

Fig. 2. (Color online) First principal strain at panels with different ratio of thicknesses $s_{s} / s_{c}=1$ (a) and $s_{s} / s_{c}=2$ (b). 
of inclination increases, the depth of the fold increases. The increase in holding time at a given maximum gas pressure allows reducing the depth of the fold. When the thickness of the skin sheet exceeds the thickness of the core sheet by 2 times, the angle of inclination of the stiffeners practically does not affect the formation of folds.

Acknowledgements. The present work was accomplished according to the state assignment of IMSP RAS No. AAAA-A17-117041310221-5.

\section{References}

1. Patent US No. 927817, 23.12.1975.

2. Superplastic Forming of Structural Alloys: Proceedings of a symposium (ed. by N.E. Paton, C.H. Hamilton). Warrendale, PA, TMS-AIME (1982) $414 \mathrm{p}$.

3. W.D. Brewer, R.K. Bird, T.A. Wallace. Materials Science and Engineering. A243, 299 (1998). Crossref

4. J.D. Beal, R. Boyer, D. Sanders. Forming of Titanium and Titanium Alloys. In: ASM Handbook, Vol. 14B, Metalworking: Sheet Forming (ed. by S. L. Semiatin). Ohio, Materials Park, ASM International (2006) pp. 656-669. Crossref

5. L.D. Hefti. Journal of Materials Engineering and Performance. 17 (2), 178 (2007). Crossref

6. A. Akhunova, S. Dmitriev, A. Kruglov, R. Safiullin. Deformatsiya i Razrushenie Materialov. 11, 41 (2012). (in Russian)
7. J. Shao, Z.Q. Li, H. Xu, X. Han, R. Zhang. Materials Science Forum. 838 - 839, 585 (2016). Crossref

8. J.-H. Cheng, S. Lee. J. Mater. Process. Technol. 45, 249 (1994). Crossref

9. Patent EP No. 0568201, 01.04.1993.

10. M. W. Turner, I. J. Andrews. 4th European Conference on Superplastic Forming Euro SPF'05. In: Book of Papers. London, United Kingdom, IOM Communications Ltd. (2005) pp. $39-46$.

11. B. Zhao, Z. Li, H. Hou, J. Liao, B. Bai. Rare Metal Materials and Engineering. 39 (6), 0963 (2010). Crossref

12. A. Pashkevich, A. Orekhov, V. Smirnov. Izv. VUZ. Aviatsionnaya Tekhika. 4, 90 (1985). (in Russian)

13. V. Smirnov, N. Birukov, V. Sadkov, I. Rostkovskii. Aviatsionnaya Industriya. 9, 46 (1986). (in Russian)

14. A. V. Kolesnikov, A. K. Shmakov. Vestnik IrGTU. 82 (11), 53 (2013). (in Russian)

15. P. Anderson. Materials Science Forum. 838-839, 621 (2016). Crossref

16. O. Valiakhmetov, R. Galeev, V. Ivanko et al. Nanotechnologies in Russia. 5 (1-2), 108 (2010). Crossref

17. V. Ganieva, A. Kruglov, R. Lutfullin, O. Rudenko, F. Enikeev. IOP Conf. Ser. Mater. Sci. Eng. 447, 012050 (2018) . Crossref

18. A. A. Kruglov, A.F. Karimova, F. U. Enikeev. Letters on materials. 8 (2), 68 (2018). Crossref

19. F. U. Enikeev. Russian Journal of Non-Ferrous Metals. 49 (1), 41 (2008). $\underline{\text { Crossref }}$

20. F. U. Enikeev, A.A. Kruglov. International Journal of Mechanical Sciences. 37 (5), 483 (1995). Crossref 